\title{
An Extended FMEA Model for Exploring the Potential Failure Modes: A Case Study of a Steam Turbine for a Nuclear Power Plant
}

\author{
Huai-Wei Lo $\mathbb{D}^{1}{ }^{1}$ James J. H. Liou $\mathbb{D},^{2}$ Jen-Jen Yang, ${ }^{1,3}$ Chun-Nen Huang $\mathbb{D},{ }^{4}$ \\ and Yu-Hsuan $\mathbf{L u}^{2}$ \\ ${ }^{1}$ Department of Business Administration, Chaoyang University of Technology, Taichung, Taiwan \\ ${ }^{2}$ Department of Industrial Engineering and Management, National Taipei University of Technology, Taipei, Taiwan \\ ${ }^{3}$ Department of Industrial Education and Technology, National Changhua University of Education, Changhua, Taiwan \\ ${ }^{4}$ Department of Fire Science, Central Police University, Taoyuan, Taiwan
}

Correspondence should be addressed to James J. H. Liou; jamesjhliou@gmail.com

Received 15 September 2021; Revised 1 December 2021; Accepted 15 December 2021; Published 27 December 2021

Academic Editor: Alireza Amirteimoori

Copyright ( $) 2021$ Huai-Wei Lo et al. This is an open access article distributed under the Creative Commons Attribution License, which permits unrestricted use, distribution, and reproduction in any medium, provided the original work is properly cited.

Critical types of infrastructure are provided by the state to maintain the people's livelihood, ensure economic development, and systematic government operations. Given the development of ever more complicated critical infrastructure systems, increasing importance is being attached to the protection of the components of this infrastructure to reduce the risk of failure. Power facilities are one of the most important kinds of critical infrastructure. Developing an effective risk detection system to identify potential failure modes (FMs) of power supply equipment is crucial. This study seeks to improve upon prior approaches for risk assessment by proposing a hybrid risk-assessment model using the concepts of failure mode and effect analysis (FMEA) and multiple-criteria decision-making (MCDM). The proposed model includes a cost-based factor for decision-makers. The subjectivity and uncertainty in FM assessment are adjusted through the rough number method. The original risk priority number (RPN) can be expanded by including the entropy weights in the risk index. Furthermore, to rank the risk priorities in a rational manner, a modified technique for order preference by similarity to ideal solution (modified TOPSIS) is adopted. The applicability and effectiveness of the proposed method were demonstrated by considering an example of a turbine steam engine in a nuclear power plant.

\section{Introduction}

Critical infrastructure networks, such as technological networks, information and communication technology systems, transport networks, health care systems, and finance and government systems, are vital assets for every country $[1,2]$. When a piece of critical infrastructure is destroyed, degraded, or rendered unavailable, lives can be lost, and economic development can be hindered. For example, in mid-August 2017, a large-scale unexpected power outage occurred in Taiwan. The primary reason for this incident was that the supply pipeline for the power supply plant stopped operating, which resulted in a large number of generator sets being shut down. The resultant blackout indirectly caused one death and multiple injuries. The area affected by the incident included a metropolitan area with a high population concentration. The main effects of the blackout included the suspension of business operations in the area and loss of road lighting leading to traffic congestion. To avoid critical infrastructure failure events like this, many countries have begun to focus considerable efforts on protecting critical infrastructure [2]. Interest in the field of risk analysis has grown in recent years, and risk assessment has emerged as a reliable and stable process that supplements and complements many aspects of citizens' lives $[3,4]$.

Critical infrastructure systems are interdependent, and the infrastructure for producing electrical power is the key system powering the functioning of other facilities $[5,6]$. The efficiency of nuclear power generation is higher than that of 
other power supply systems. One of the main pieces of power generation equipment for nuclear power plants is the turbine steam engine [7]. If the potential for failures can be detected before a failure incident occurs, maintenance measures and improvement strategies can be developed to effectively reduce the probability of failure. This is the purpose of the failure mode and effect analysis (FMEA). FMEA is one of the most popular risk detection tools used to identify, assess, and remove potential or known failure modes (FMs) to improve the safety and robustness of intricate systems. $t$ is intended to provide suggestions for risk management decisions [8-10].

Basically, potential FMs in FMEA are assessed and sorted according to the risk priority number (RPN), which is obtained by multiplying three risk elements: severity $(S)$, occurrence $(O)$, and detection $(D)$ [11-13]. Unfortunately, cost, which is often of most concern to the organization or enterprise, is not included as a risk element in the FMEA [8]. In addition, there are only a few FMEA studies that discuss the failure analysis of steam turbines in nuclear power plants.

However, there are problems with the method for determining RPN values when FMEA is applied to real-world problems. The method has been criticized because of the equal weightings of its elements, its high duplication rate, and its failure to address the subjective perceptions from analysts. These shortcomings can significantly affect the accuracy of the analysis results $[8,14]$. It is also the case that many current FMEA models use arithmetic averaging to integrate the judgments of multiple experts/decisionmakers/analysts. This means that outliers/extreme values are ignored [9].

This study develops an extension of the FMEA model aimed at enhancing the effectiveness of the methodology. Multiple-criteria decision-making (MCDM) techniques that use analysts' experience and judgment to strengthen the risk assessment process are utilized for making critical risk management strategies to enhance the efficacy and empirical validity of risk analysis results. Numerous MCDM models have been proposed to improve the FMEA methodology $[15,16]$. The methods for determining the weights of three risk elements include the analytic hierarchy process (AHP) [17], the analytic network process (ANP) [18], data envelopment analysis (DEA) [19], and the best worst method (BWM) [8]. The FM sorting methods include the technique for ordering preference by similarity to ideal solution (TOPSIS) [9], grey relational analysis (GRA) [8], and VIsekriterijumska Optimizacija i Kompromisno Resenje (VIKOR) [20]. FMEA methods using MCDM techniques have been increasingly used for solving real-world cases in recent years. In one study, a hierarchical MCDM approach based on the fuzzy concept and the VIKOR technique was proposed to deal with site evaluation in municipal solid waste management systems [21]. Silva et al. [22] proposed an approach for risk assessment of information security encompassing FMEA and fuzzy set theory. A modified VIKOR method was used to explore the effects of FMs. Researchers have applied the AHP method based on the decision-making trial and evaluation laboratory
(DEMATEL) to obtain the influential weights [11]. Instead of calculating the RPN, Safari et al. [23] prioritized risk elements by using fuzzy VIKOR because of the drawbacks of the conventional FMEA method. Mohsen and Fereshteh [14] applied the $Z$-number technique to reflect the inherent uncertainty in decision-makers' perceptions and the Shannon entropy method to obtain objective weights. A fuzzy VIKOR approach was applied to prioritize the potential risks. Previous studies have significantly advanced risk analysis with fuzzy linguistic information. However, if a riskassessment model is developed without suitably considering the comprehensive risk elements, the model may produce inaccurate solutions, which could lead to confusion in FM ranking.

In this study, a novel priority model is proposed by applying MCDM methods for FM assessment and ranking in FMEA. In addition, a risk element called the expected cost $(E)$ is added to the process of evaluating the RPN value for financial considerations. The four elements exploited in the FMEA implementations encompass the large range of causal factors leading to an FM, which can reduce the probability of mistakes, uncertainties, and ambiguities in evaluation. The proposed method includes three important steps. In the first step, the concept of rough numbers is employed to handle the uncertainty, subjectivity, and fuzziness arising from the analysts' subjective perceptions and differences in experience during the risk-assessment process. Instead of using the arithmetic mean to obtain crisp values, the rough number is used to effectively integrate analyst information for forming a set of interval values. Next, the entropy technique is employed to generate the objective weights of each risk element. The modified TOPSIS technique is then applied to rank the FMs. In contrast to the traditional TOPSIS, all the alternatives and weight preferences are considered in the modified TOPSIS. Finally, a numerical example of critical infrastructure is shown to illustrate the real application of the proposed model. This study can provide a reference for the industry or organizations to evaluate and prioritize risk in different scenarios. The contributions of this study and the advantages of this methodology are summarized below:

(i) Entropy is used to assign the weight of the risk elements according to the FM assessment data. The proposed model does not require a pairwise comparison questionnaire of risk elements to be issued.

(ii) The increased expected cost is considered a risk element, the inclusion of which enhances the riskassessment ability of the FMEA.

(iii) The proposed extended FMEA model effectively assesses the potential FMs of nuclear power plants.

(iv) The proposed FMEA model can be applied to other kinds of critical infrastructure. The time and quality of the analysis are not affected by an increase in the criteria and alternatives.

The remainder of the article is organized as follows. A review of the literature on critical infrastructure, risk analysis, and FMEA is presented in Section 2. The research 
methodology is discussed in Section 3. A real-world case study demonstrating the application of the proposed model is presented in Section 4. Section 5 describes the results and subsequent discussion. Finally, some conclusions and suggestions for future work are presented.

\section{Literature Review}

This section briefly reviews the topics related to this study, including the interdependence of critical infrastructure systems, type of risk analysis, and FMEA.

\subsection{Interdependence of Critical Infrastructure Systems.} Critical infrastructure refers not to a single facility but to a collection of numerous facilities, including water, energy, information, telecommunication, financial, transportation, government, and emergency rescue systems [13, 24]. Critical infrastructure is the backbone of the economy in many countries. Energy sustainability, as well as economic and social development, cannot be achieved if the operations of critical infrastructure are at risk of damage or disruption [25]. In recent years, natural disasters and terrorist attacks have been frequently reported, and infrastructure systems have failed, which affects the functioning of all aspects of society [1].

Interdependencies between systems vary widely, and according to their characteristics and effects on infrastructure agents, there are four main categories of interdependencies: cyber, geographic, physical, and logical interdependencies [4]. Geographic interdependency occurs when components of multiple structures are in close spatial proximity. Physical interdependency is related to material flows among infrastructures. Cyber interdependency occurs when a state relies on information transmitted through the internet infrastructure. Logical interdependency includes all types of interdependencies that are not cyber, physical, or geographic connections. Therefore, the reliability of each component of critical infrastructure is the basis of all protective operations.

Huang et al. [5] noted that most types of critical infrastructure are interrelated, but the loss of the electrical power supply is a major factor affecting other infrastructure systems. For example, the water supply, communication, and transportation systems require the provision of electricity to maintain normal operations. Wang et al. [6] proposed a critical infrastructure responsibility framework based on the concept of ethics. In today's high-tech society, electricity is the most basic energy demand, without which all communication systems fail. Große and Olausson [26] believed that when electrical equipment is unavailable, an increasing number of disaster events, such as the interruption of financial transactions, blocked transportation, and failure to monitor security, would occur that would affect society. Therefore, they called for strengthening the protection of energy infrastructure. Developing a comprehensive risk analysis method before an unpredicted disaster occurs can significantly reduce reconstruction costs.
2.2. Type of Risk Analysis. There are two types of risk assessment methods: quantitative and qualitative risk analysis approaches. Quantitative risk analysis methods, such as the proportional risk-assessment technique $[27,28]$ and the decision matrix risk-assessment technique [10], use the value obtained from mathematical and statistical equations to represent the degree of risk. However, it is difficult to conduct risk evaluation by using mathematical measures because of the complicated structures and widespread usage of information systems. Qualitative risk assessment such as in the FMEA what-if analysis method [12] is based on analyst interviews, and evidence-based results are obtained through soft computing tools rather than mathematical calculations alone.

One major drawback of qualitative risk analysis is that it often does not yield exactly the same results. Furthermore, because qualitative methods do not apply mathematical tools to model the risk, the risk-assessment results are quite dependent on the perceptions of the people who conduct the risk evaluation. The danger of obtaining subjective results when employing qualitative risk analysis approaches exists. Today's information systems have more complicated structures than previous information systems and more widespread usage. Consequently, the intensive mathematical measures used to model risk for complex environments make the risk-assessment process increasingly difficult. Quantitative methods may actually increase the difficulty of the evaluation process. Risk assessment tools based on qualitative measures are more appropriate than other riskassessment methods for today's intricate risk environment of information systems [10, 29]. A hybrid risk-assessment model is proposed in this study based upon the concepts of qualitative risk analysis, FMEA, and rough numbers. The rough number technique is applied to handle subjectivity and uncertainty, which are significant weaknesses in qualitative risk evaluation.

2.3. FMEA. The purpose of FMEA is to identify all possible risk elements and assess their causes as well as their subsequent effects on the function of the system under consideration [9]. FMEA is a reliable qualitative method applied for accident prevention and risk detection. This technique can be applied to discover and eliminate recognized or potential FMs to enhance the robustness and safety of complex products or systems [8]. In contrast to other risk analysis tools, the major focus of FMEA is to engage in proactive prevention rather than finding a solution after system failure occurs. This proactive prevention can help decision-makers adjust existing strategies, add compensatory provisions, apply the recommended actions to decrease the likelihood of failures, reduce the probability of risk, and minimize accident hazards [11, 12]. Due to its effectiveness, FMEA has been widely applied and proven to be successful in many fields related to the knitting process [30], the aerospace [31], automotive [32], and medical [33] industries, to name a few $[34,35]$. The most common way to assess the risk of failure in FMEA involves determining the RPN, which is the product of the $S, O$, and $D$. However, when 
applied in real-world problems, the crisp RPN method also has some shortcomings and limitations. The limitations of the conventional FMEA model are as follows $[8,9,11,17,36]$ :

(i) The three elements applied in FMEA analysis do not encompass the entire range of causal risk elements

(ii) The measurement of $S$ and $D$ is relative and subjective, with no holistic characterization of group judgment

(iii) The $S, O$, and $D$ are difficult to evaluate precisely in numerical form

(iv) The $S, O$, and $D$ are often given no or equal importance weights

(v) RPN values are not continuous, and there exists no mechanism to interpret the meaning of the differences among different RPNs

(vi) Different combinations of $S, O$, and $D$ may produce the same RPN, thereby causing some highrisk FMs to be ignored

(vii) Many numbers in the 1-1,000 range cannot be formed from the product of $S, O$, and $D$

(viii) Small variations in each rating may lead to considerably different effects on the RPN

The conventional FMEA method has been proven to be one of the most important early preventative initiatives for systems, processes, and services; however, the aforementioned limitations may reduce the reliability of the conventional FMEA model. To deal with the drawbacks of the conventional FMEA model, the entropy-based rough FMEA method is proposed. A detailed introduction of the proposed method is provided in Section 3, and the practical application of the proposed method is described in Section 4.

\section{Proposed Extended FMEA Model}

In this section, we introduce the mathematical tools used in the proposed method, including rough numbers, entropy, and the modified TOPSIS method. The analysis process of the proposed model is illustrated in Figure 1.

3.1. Determination of Risk Elements. The $S, O$, and $D$ used in the FMEA execution process do not encompass the entire range of causative risk elements that need to be considered during decision-making. An increasing number of decisionmakers also consider the expected cost when prioritizing FM for prevention. Therefore, for a more comprehensive evaluation of the FMs, the proposed FMEA is not limited to the conventional three risk elements. An additional risk element, namely the expected cost $(E)$, is added as a criterion for decision-making. During the risk assessment procedure, analysts selected a linguistic term to describe the degree of $S, O, D$, and $E$ for every FM. The corresponding scores for these terms are presented in Table 1. If an analyst decided that the expected cost for a specific FM was close to the original price, the relative score for the expected cost for that FM would be 10. For

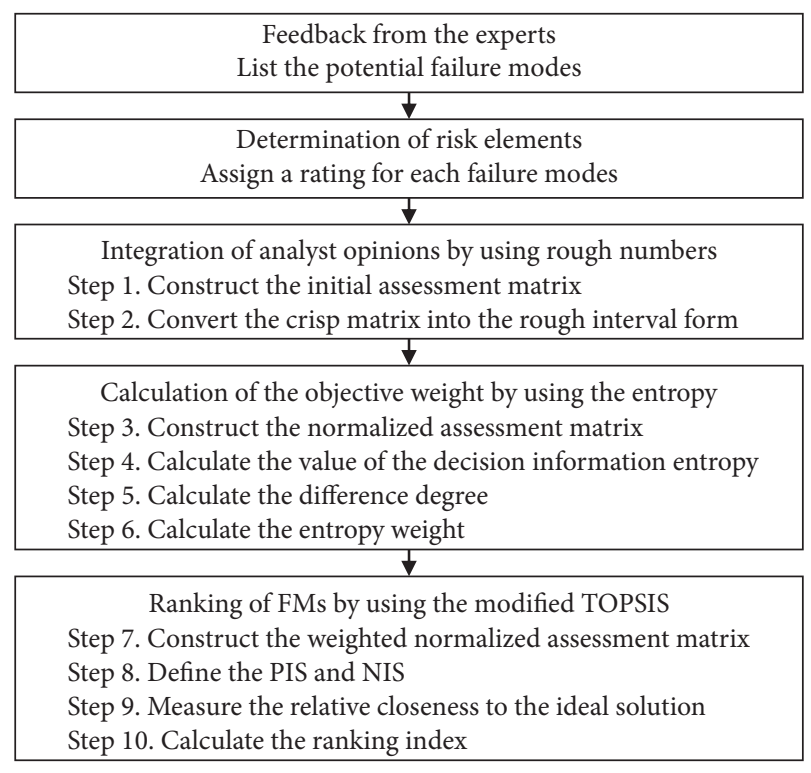

Figure 1: Analysis process of the proposed model.

example, turbine blade breakage is hazardous $(\mathrm{H})$, and the maintenance cost when the blade fails is extremely high (EH); however, risk detection is very high $(\mathrm{VH})$, and the failure does not occur frequently (very slight, VS). The assessment score would thus be represented as follows: $S: 10, O: 3, D: 2$, and $E: 9$.

\subsection{Integration of Analyst Opinions by Using Rough Numbers.} In practice, FM evaluation is an uncertain and subjective group decision-making process because the analysts on the FMEA team judge the importance of risk elements and assess different FMs according to their own knowledge and experience. Thus, practitioners and engineers should find a reliable method to solve the problems of the analysts' subjectivity as well as uncertain or insufficient information. As a new soft computing tool for adjusting the uncertainty and ambiguity of information, rough numbers can provide potential new knowledge without any prior information as well as a relatively objective and reasonable description of the decision issue.

The rough number method is a mathematical extension of the rough set theory proposed by Pawlak [37] and an effective tool for handling vague, imprecise, and uncertain information. There is some overlap with several other theories for dealing with fuzziness and uncertainty, especially with fuzzy set theory. Nevertheless, rough numbers can be viewed as an independent and complementary discipline [38]. The steps involved in the rough number method are described in the following explanation.

\subsubsection{Step 1: Construct the Initial Assessment Matrix.} After obtaining the corresponding scores of risk elements from the linguistic form (see Table 1), the analyst assesses the risk scores of all FMs. Suppose the FMEA team has $k$ analysts, $i \mathrm{FMs}$, and $j$ risk elements, where $k=1,2, \ldots, p ; i=1$, $2, \ldots, m$; and $j=1,2, \ldots, n$. The initial assessment matrix $A$ is represented as follows: 
TABLE 1: Corresponding scores of linguistic terms [9].

\begin{tabular}{lcccc}
\hline Severity & Occurrence & Detection & Expected cost & Corresponding scores \\
\hline No (N) & Almost never (AN) & Almost certain (AC) & Almost no cost (N) & 1 \\
Very slight (VS) & Remote (R) & Very high (VH) & Remote (R) & 2 \\
Slight (S) & Very slight (VS) & High (H) & Low (L) & 3 \\
Minor (MI) & Slight (S) & Moderately high (MH) & Relatively low (RL) & 4 \\
Moderate (MO) & Low (L) & Moderate (M) & Moderate (M) & 5 \\
Significant (SI) & Medium (M) & Low (L) & Moderately high (MH) & 6 \\
Major (M) & Moderately high (MH) & Very low (VL) & High (H) & 7 \\
Extreme (E) & High (H) & Remote (R) & Very high (VH) & 8 \\
Serious (SE) & Very high (VH) & Very remote (VR) & Extremely high (EH) & 9 \\
Hazardous (H) & Almost certain (AC) & Absolute uncertainty (VU) & Almost or close to original price (O) & 10 \\
\hline
\end{tabular}

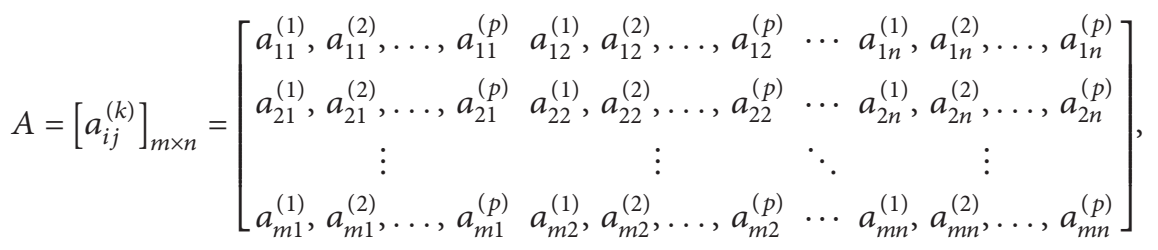

where $a_{\mathrm{ij}}^{(k)}$ represents the score provided by $\mathrm{RN}(A)$ analyst $k$ for FM $i$ under risk element $j$.

\subsubsection{Step 2: Convert the Crisp Matrix into the Rough Interval} Form. Next, the rough assessment matrix $\mathrm{RN}(A)$ is generated by converting the crisp assessment score into the rough interval form to generate the rough assessment matrix. The rough number calculation is discussed in detail in Lo et al. [9].

$$
R N(A)=\left[a_{i j}^{L}, a_{i j}^{U}\right]_{m \times n}=\left[\begin{array}{cccc}
{\left[a_{11}^{L}, a_{11}^{U}\right]} & {\left[a_{12}^{L}, a_{12}^{U}\right]} & \cdots & {\left[a_{1 n}^{L}, a_{1 n}^{U}\right]} \\
{\left[a_{21}^{L}, a_{21}^{U}\right]} & {\left[a_{22}^{L}, a_{22}^{U}\right]} & \cdots & {\left[a_{2 n}^{L}, a_{2 n}^{U}\right]} \\
\vdots & \vdots & \ddots & \vdots \\
{\left[a_{m 1}^{L}, a_{m 1}^{U}\right]} & {\left[a_{m 2}^{L}, a_{m 2}^{U}\right]} & \cdots & {\left[a_{m n}^{L}, a_{m n}^{U}\right]}
\end{array}\right],
$$

where $a_{\mathrm{ij}}^{L}$ and $a_{\mathrm{ij}}^{U}$ represent the rough upper and lower bounds, respectively. The rough matrix is defuzzified for subsequent entropy and modified TOPSIS operations, as given in equation (4). The final assessment matrix $Y$ is represented as follows:

$$
\begin{aligned}
& Y=\left[y_{i j}\right]_{m \times n}=\left[\begin{array}{cccc}
y_{11} & y_{12} & \cdots & y_{1 n} \\
y_{21} & y_{22} & \cdots & y_{2 n} \\
\vdots & \vdots & \ddots & \vdots \\
y_{m 1} & y_{m 2} & \cdots & y_{m n}
\end{array}\right], \\
& y_{i j}=\frac{a_{i j}^{L}+a_{i j}^{U}}{2} .
\end{aligned}
$$

3.3. Calculation of the Objective Weight by Using the Entropy. In this study, the entropy method was used to eliminate the problem of no or equal relative weights for different risk elements and generate the objective weight of the assessment indicators in FMEA.

The entropy method originated from the thermodynamics field and was initially used to describe the irreversible phenomenon of a motion or process. Shannon [39] then introduced the entropy method into information theory. Entropy is defined as the degree of uncertainty in a random variable. Therefore, the entropy method can be used to determine the degree of disorder and its utility in the system information. If the evaluated parameters have a considerable dissimilarity from each other for a specific risk element, the entropy is small, which indicates that the risk element provides effective information and should be assigned a large weight. By contrast, the smaller the dissimilarity, the larger the value of the entropy weight.

The entropy approach is based on inherent information and is used to obtain the index objective weight. Thus, the method can eliminate the effect of subjective elements and provide a reasonable solution. When adopting the entropy method, only one calculation needs to be performed to obtain a set of weights suited for all FMs. 
The entropy method is generally used in the problem of supplier selection; however, in this study, the entropy method was adopted to obtain the weight of the risk-assessment factors in FMEA. The process of calculation is described below.

3.3.1. Step 3: Construct the Normalized Assessment Matrix. The final assessment matrix $Y$ is obtained through rough number calculation. The matrix is used to normalize the rating through equation (5) for eliminating the effect of the rating dimension on incommensurability. Many normalized approaches exist, but in this study, the following equation is selected for normalization:

$$
r_{i j}=\frac{y_{i j}}{\sqrt{\sum_{i=1}^{m} y_{i j}^{2}}} .
$$

3.3.2. Step 4: Calculate the Value of the Decision Information Entropy. The evaluation information for each risk element can be represented by

$$
f_{j}=-k \sum_{i=1}^{m} r_{i j} \ln r_{i j},
$$

where $k=(1 / \ln n)$.

3.3.3. Step 5: Calculate the Difference Degree. The difference degree is calculated using

$$
g_{j}=1-f_{j}
$$

3.3.4. Step 6: Calculate the Entropy Weight. The entropy weight of the risk element $j$ index is determined using

$$
w_{j}=\frac{g_{j}}{\sum_{j=1}^{n} g_{j}} .
$$

In this study, the entropy weight represents useful information of the risk-evaluating factors. Consequently, the larger the entropy weight, the more useful the risk element.

3.4. Ranking of FMs by Using the Modified TOPSIS. Due to the drawbacks of the conventional FMEA method mentioned in Section 2, a more comprehensive and flexible FMEA approach for ranking potential risk elements is proposed in this section. The proposed method is based on the traditional TOPSIS, with some modifications made to eliminate flaws. The modified TOPSIS was then used to solve the problem of crisp multiplication in the traditional FMEA.

The TOPSIS technique, which was proposed by Hwang and Yoon [40], has been widely applied in different research areas. The TOPSIS approach is a ranking method based on the concept of a compromise solution. We attempted to determine the solutions farthest from the negative ideal solution (NIS) and nearest to the positive ideal solution (PIS) simultaneously. In the past decades, many studies have attempted to extend the TOPSIS. The modified TOPSIS method used in this study was proposed by Kuo [41]. The ranking index in the traditional TOPSIS does not consider the weights of the separations of an alternative from the PIS and NIS. Therefore, Kuo [41] proposed a new ranking index to deal with this drawback. The proposed solution steps are as follows:

3.4.1. Step 7: Construct the Weighted Normalized Assessment Matrix. The weighted assessment matrix $V$ is determined by multiplying the normalized assessment elements $r_{\mathrm{ij}}$ and the corresponding entropy weights $w_{j}$, as given in the following equation:

$$
v_{i j}=r_{i j} \cdot\left(w_{j}\right)
$$

3.4.2. Step 8: Define the PIS and NIS. The PIS is composed of the maximum of every risk element from the weighted decision matrix, and the NIS is composed of the minimum of every risk element from the weighted decision matrix. The PIS and NIS are determined as follows:

$$
\begin{aligned}
\mathrm{PIS} & =\left\{v_{1}^{+}, v_{2}^{+}, \ldots, v_{j}^{+}, \ldots, v_{n}^{+}\right\}, \\
\mathrm{NIS} & =\left\{v_{1}^{-}, v_{2}^{-}, \ldots, v_{j}^{-}, \ldots, v_{n}^{-}\right\} .
\end{aligned}
$$

3.4.3. Step 9: Measure the Relative Closeness to the Ideal Solution. The distance of every feasible solution from the PIS and NIS is determined using equations (11) and (12), respectively. In this paper, the PIS and NIS are expressed as the highest risk and the lowest risk, respectively. This can facilitate decision-makers to understand the relative risks of these failure modes.

$$
\begin{aligned}
& d_{i}^{+}=\sqrt{\sum_{j=1}^{n}\left(v_{j}^{+}-v_{i j}\right)^{2},} \\
& d_{i}^{-}=\sqrt{\sum_{j=1}^{n}\left(v_{i j}-v_{i j}^{-}\right)^{2} .}
\end{aligned}
$$

3.4.4. Step 10: Calculate the Ranking Index. Compared with the traditional TOPSIS, the modified TOPSIS, which is presented in equation (13), has two advantages in the decision-making process. First, the "relative importance" is considered for two criteria in the modified TOPSIS by adding weights. Thus, if a decision-maker prefers to separate an alternative from the PIS, the modified TOPSIS can provide a different ranking index that caters to the requirements. Second, the ranking index is more comprehensive, thus avoiding the unrecognized ranking of certain alternatives.

In attempting to find a compromise solution, the ranking index in equation (13) is more intelligible than and superior to the original TOPSIS. The calculation process of the ranking index $\left(\mathrm{RC}_{i}\right)$ is given as follows: 


$$
\mathrm{RC}_{i}=w^{+}\left(\frac{d_{i}^{-}}{\sum_{i=1}^{m} d_{i}^{-}}\right)-w^{-}\left(\frac{d_{i}^{+}}{\sum_{i=1}^{m} d_{i}^{+}}\right)
$$

where $w^{+}$and $w^{-}$denote the weights that reflect the corresponding importance of the two separation measures obtained from the decision-makers.

\section{Empirical Case: Steam Turbine at a Nuclear Power Plant}

The proposed methodology was applied to an empirical case for a steam turbine in a nuclear power plant. The smooth functioning of a steam turbine is essential for the reliability and stability of operations in a nuclear power plant. A steam turbine is simply a heat engine that performs mechanical work by using steam as its working fluid. Compared with traditional steam engines of the reciprocating type, steam turbines have considerable improved heat transfer efficiency and are commonly used in thermal and nuclear power plants. To ensure the reliability of the turbine system, the potential FMs of the system should be evaluated, and risk assessment conducted. The effectiveness of the proposed FMEA model was verified by comparison with the conventional FMEA approach.

4.1. Survey Data. This study investigated a nuclear power plant in Taiwan as an example to demonstrate the usefulness and practicability of the proposed FMEA model. The FMEA team consisted of 24 analysts, including government regulators, professors in the relevant fields, and nuclear power plant engineers. Each analyst had at least 10 years of work experience in the nuclear power industry. Currently, two major nuclear power plants are in operation in Taiwan. The occurrence of unplanned downtime at a nuclear power plant has a significant impact on the functioning of society. Nuclear power plants contain numerous and complex pieces of equipment, but we selected the most critical component, namely the "steam turbine," for investigation. Twelve major potential FMs were identified for nuclear power plants by the group of analysts: high temperature of the engine $\left(\mathrm{FM}_{1}\right)$, clogged lubricating oil system $\left(\mathrm{FM}_{2}\right)$, foreign objects within the system $\left(\mathrm{FM}_{3}\right)$, fracture of the vane $\left(\mathrm{FM}_{4}\right)$, loose valve $\left(\mathrm{FM}_{5}\right)$, bearing damage $\left(\mathrm{FM}_{6}\right)$, broken chassis $\left(\mathrm{FM}_{7}\right)$, mechanical transmission breakdown $\left(\mathrm{FM}_{8}\right)$, rotor breakdown $\left(\mathrm{FM}_{9}\right)$, sensor malfunction $\left(\mathrm{FM}_{10}\right)$, leakage of the pipeline $\left(\mathrm{FM}_{11}\right)$, and measurement instrument breakdown $\left(\mathrm{FM}_{12}\right)$.

4.2. Ranking Priority of FMs. After identifying the major potential FMs, the 24 analysts subjectively ranked the importance of these risk elements using a questionnaire format. To save space, we have only presented one criterion, namely the severity scores of analysts for the 12 FMs (Table 2).

The rough assessment matrix comprises the interval values obtained from the analysts' feedback, which includes the uncertainty of their subjective judgments. The rough number method provides a larger amount of implicit information than the arithmetic mean method does. The rough assessment matrix (Table 3) can be obtained using equations (1) and (2). Here, use the fourth FM $\left(\mathrm{FM}_{4}\right)$ as a rough number calculation case, as shown in Appendix A.

Using equations (3) and (4), the intervals obtained from Table 3 were transformed into final crisp values. Then, by executing the entropy calculation program described in Section 3.3 (equations (5)-(8)), the weights of the risk elements were obtained as follows: $w_{S}=0.4925, w_{O}=0.1944$, $w_{D}=0.0806$, and $w_{E}=0.2325$. The severity $(S)$ was rated as the most important risk element, with a weight value of 0.4926 . The expected cost $(E)$ was the second most important risk element, which indicated that cost considerations are necessary for critical infrastructure risk-assessment systems. In fact, the government allocates maintenance budgets for critical infrastructure in specific cycles. Finally, the modified TOPSIS was used to calculate the ranking of the FMs, as described in Section 3.4. Table 4 presents the ranking, $d_{i}^{+}$ value, and $d_{i}$ value of the FMs.

4.3. Results and Management Implications. Steam turbines are a key mechanism for energy conversion in nuclear power plants. According to the information provided by the 24 experts, the results of our analysis indicate that rotor breakdown $\left(\mathrm{FM}_{9}\right)$, fracture of the vane $\left(\mathrm{FM}_{4}\right)$, foreign objects $\left(\mathrm{FM}_{3}\right)$, a clogged lubricating oil system $\left(\mathrm{FM}_{2}\right)$, bearing damage $\left(\mathrm{FM}_{6}\right)$, and mechanical transmission breakdown $\left(\mathrm{FM}_{8}\right)$ are the top $6 \mathrm{FMs}$ leading to the failure of steam turbines. The modified TOPSIS can provide the relative risk level of the FMs through the ranking index $\left(\mathrm{RC}_{i}\right)$. Because the sum of $\mathrm{RC}_{i}$ is equal to 0 , when $\mathrm{RC}_{i}$ is greater than 0 , the FMs have a high-risk level. For example, rotor breakdown $\left(\mathrm{FM}_{9}\right)$ is the highest-ranking FM. This mode has the shortest distance from the PIS $\left(d_{9}^{+}=0.0396\right)$ and farthest distance from the NIS $\left(d_{9}^{-}=0.1083\right)$. In addition, $\mathrm{RC}_{9}$ is positive and represents the largest ranking index (0.0391) of the FMs.

The purpose of FMEA is captured in the phrase "An ounce of prevention is worth a pound of cure." The results of FMEA can provide engineers with guidance as to what precautionary measures should be taken before an accident occurs. We conducted detailed interviews with the analysts to identify the prevention methods for the six aforementioned FMs. Several inspection and maintenance measures were obtained, as presented in Table 5.

4.4. FMEA Model Comparison. To demonstrate the effectiveness of the proposed method, it was compared with the conventional and cost-based RPN methods. In the conventional RPN method, which is based on an engineering perspective, $S, O$, and $D$ are multiplied. In the cost-based RPN method, the expected cost is considered as a risk element, and then $S, O, D$, and $E$ are multiplied. Both the costbased RPN and proposed methods consider the management perspective to reflect the actual budget constraints of risk management. The calculation results obtained with the three approaches are listed in Table 6.

The correlation coefficient between the ranking results of the conventional and cost-based RPN methods was 0.78 , which indicates that the ranking results 
TABLe 2: Crisp severity $(S)$ ratings from the analysts for the 12 FMs.

\begin{tabular}{|c|c|c|c|c|c|c|c|c|c|c|c|c|}
\hline Analysts & $\mathrm{FM}_{1}$ & $\mathrm{FM}_{2}$ & $\mathrm{FM}_{3}$ & $\mathrm{FM}_{4}$ & $\mathrm{FM}_{5}$ & $\mathrm{FM}_{6}$ & $\mathrm{FM}_{7}$ & $\mathrm{FM}_{8}$ & $\mathrm{FM}_{9}$ & $\mathrm{FM}_{10}$ & $\mathrm{FM}_{11}$ & $\mathrm{FM}_{12}$ \\
\hline 1 & SI & $\mathrm{H}$ & $\mathrm{M}$ & $\mathrm{H}$ & MI & $E$ & $\mathrm{MO}$ & $\mathrm{M}$ & $\mathrm{H}$ & $\mathrm{MO}$ & $S$ & SI \\
\hline 2 & SI & M & M & $\mathrm{H}$ & $\mathrm{M}$ & $\mathrm{H}$ & $\mathrm{SE}$ & $\mathrm{H}$ & $\mathrm{M}$ & MI & MI & $\mathrm{SE}$ \\
\hline 3 & SI & SI & M & $\mathrm{H}$ & M & SI & MI & SE & SE & VS & $\mathrm{MO}$ & $\mathrm{MO}$ \\
\hline 4 & SI & SE & SE & $\mathrm{H}$ & SI & SI & SI & SI & SE & SI & $\mathrm{MO}$ & SI \\
\hline 5 & $\mathrm{SE}$ & M & M & $\mathrm{H}$ & $\mathrm{M}$ & $\mathrm{E}$ & SE & SE & SE & $\mathrm{MO}$ & $\mathrm{MO}$ & $\mathrm{MO}$ \\
\hline 6 & $\mathrm{MO}$ & M & $\mathrm{H}$ & $\mathrm{H}$ & $\mathrm{MO}$ & M & $\mathrm{H}$ & $\mathrm{E}$ & SE & S & $\mathrm{MO}$ & $\mathrm{MO}$ \\
\hline 7 & $\mathrm{~S}$ & M & SE & $\mathrm{H}$ & SI & SI & SE & SE & SE & $S$ & S & $\mathrm{MO}$ \\
\hline 8 & SI & SE & $\mathrm{H}$ & $\mathrm{H}$ & $\mathrm{MO}$ & $\mathrm{H}$ & SI & S & $\mathrm{H}$ & $S$ & $S$ & S \\
\hline 9 & SI & SE & SE & $\mathrm{H}$ & SI & M & SE & SE & $\mathrm{H}$ & SI & $\mathrm{M}$ & SI \\
\hline 10 & $\mathrm{MO}$ & SE & SI & $\mathrm{H}$ & SI & M & SI & SI & SE & $\mathrm{MO}$ & SE & SI \\
\hline 11 & $\mathrm{M}$ & SE & M & M & M & M & $\mathrm{MO}$ & M & $\mathrm{M}$ & $\mathrm{MO}$ & $\mathrm{MO}$ & $\mathrm{MO}$ \\
\hline 12 & $\mathrm{MO}$ & SE & SE & $\mathrm{H}$ & $\mathrm{M}$ & $\mathrm{M}$ & SI & SI & SE & $\mathrm{MO}$ & SI & $\mathrm{MO}$ \\
\hline 13 & VS & $\mathrm{M}$ & SE & $\mathrm{H}$ & $\mathrm{MO}$ & $\mathrm{M}$ & MI & $S$ & SE & S & S & $\mathrm{N}$ \\
\hline 14 & $\mathrm{M}$ & $\mathrm{E}$ & $\mathrm{E}$ & SE & $\mathrm{MO}$ & SI & SI & $\mathrm{E}$ & $\mathrm{E}$ & $\mathrm{N}$ & MI & SI \\
\hline 15 & SI & SE & $\mathrm{M}$ & SE & SI & $\mathrm{E}$ & $\mathrm{E}$ & $\mathrm{M}$ & SE & $\mathrm{MO}$ & $\mathrm{MO}$ & MI \\
\hline 16 & MI & SE & $\mathrm{M}$ & $\mathrm{E}$ & SI & $\mathrm{M}$ & SI & $\mathrm{M}$ & $\mathrm{H}$ & S & $\mathrm{MO}$ & $\mathrm{M}$ \\
\hline 17 & $\mathrm{MO}$ & $\mathrm{E}$ & SE & $\mathrm{H}$ & $\mathrm{M}$ & M & SE & SI & $\mathrm{H}$ & $S$ & $\mathrm{MO}$ & MI \\
\hline 18 & $\mathrm{M}$ & $\mathrm{M}$ & $\mathrm{E}$ & $\mathrm{E}$ & $\mathrm{E}$ & $\mathrm{E}$ & $\mathrm{E}$ & $\mathrm{E}$ & $\mathrm{E}$ & SI & $\mathrm{MO}$ & MI \\
\hline 19 & SI & $\mathrm{M}$ & $\mathrm{M}$ & SE & SI & SI & SI & $\mathrm{M}$ & SE & S & SI & S \\
\hline 20 & MI & M & SE & $\mathrm{E}$ & M & $\mathrm{M}$ & MI & $\mathrm{M}$ & SE & VS & MI & $\mathrm{M}$ \\
\hline 21 & SI & $\mathrm{E}$ & SE & $\mathrm{H}$ & M & SE & SI & M & $\mathrm{H}$ & $\mathrm{N}$ & $\mathrm{M}$ & SI \\
\hline 22 & $\mathrm{M}$ & SE & $\mathrm{E}$ & SE & $\mathrm{E}$ & SE & M & $\mathrm{E}$ & $\mathrm{M}$ & MI & SI & MI \\
\hline 23 & $\mathrm{MO}$ & SE & $\mathrm{E}$ & SE & $\mathrm{M}$ & SI & M & SI & $\mathrm{E}$ & S & M & SI \\
\hline 24 & SI & $\mathrm{H}$ & SE & SE & MI & $\mathrm{E}$ & $\mathrm{M}$ & $\mathrm{E}$ & E & MI & SI & $\mathrm{MO}$ \\
\hline
\end{tabular}

TABle 3: Rough assessment matrix.

\begin{tabular}{|c|c|c|c|c|}
\hline $\mathrm{FM}_{i}$ & $S$ & $\mathrm{O}$ & $D$ & E \\
\hline $\mathrm{FM}_{1}$ & {$[4.635,6.541]$} & {$[2.497,4.451]$} & {$[1.504,3.444]$} & {$[3.613,6.115]$} \\
\hline $\mathrm{FM}_{2}$ & {$[7.456,8.863]$} & {$[3.114,5.545]$} & {$[2.101,4.209]$} & {$[4.463,6.392]$} \\
\hline $\mathrm{FM}_{3}$ & {$[7.411,8.832]$} & {$[3.383,6.571]$} & {$[3.706,6.42]$} & {$[3.435,6.515]$} \\
\hline $\mathrm{FM}_{4}$ & {$[8.854,9.834]$} & {$[1.799,3.927]$} & {$[2.536,5.71]$} & {$[4.936,7.299]$} \\
\hline $\mathrm{FM}_{5}$ & {$[5.466,6.906]$} & {$[4.018,6.478]$} & {$[2.827,4.656]$} & {$[3.628,5.584]$} \\
\hline $\mathrm{FM}_{6}$ & {$[6.632,8.212]$} & {$[2.284,5.524]$} & {$[2.327,4.182]$} & {$[3.813,6.974]$} \\
\hline $\mathrm{FM}_{7}$ & {$[5.526,8.007]$} & {$[1.724,5.113]$} & {$[2.332,5.076]$} & {$[3.96,6.121]$} \\
\hline $\mathrm{FM}_{8}$ & {$[5.926,8.214]$} & {$[2.706,5.611]$} & {$[2.589,4.876]$} & {$[4.15,6.638]$} \\
\hline $\mathrm{FM}_{9}$ & {$[8.216,9.407]$} & {$[2.434,5.007]$} & {$[2.201,3.961]$} & {$[5.626,8.394]$} \\
\hline $\mathrm{FM}_{10}$ & {$[2.718,4.754]$} & {$[5.522,7.931]$} & {$[2.843,5.832]$} & {$[3.617,5.688]$} \\
\hline $\mathrm{FM}_{11}$ & {$[4.154,6.169]$} & {$[5.316,7.489]$} & {$[2.745,4.617]$} & {$[3.809,6.172]$} \\
\hline $\mathrm{FM}_{12}$ & {$[4.008,6.202]$} & {$[3.589,6.674]$} & {$[3.33,5.626]$} & {$[3.698,5.646]$} \\
\hline
\end{tabular}

TABLE 4: Results of the modified TOPSIS calculation.

\begin{tabular}{lcccc}
\hline $\mathrm{FM}_{i}$ & $d_{i}^{+}$ & $d_{i}^{-}$ & $\mathrm{RC}_{i}$ & Ranking $^{-}$ \\
\hline $\mathrm{FM}_{1}$ & 0.0915 & 0.0386 & -0.0329 & 0.0271 \\
$\mathrm{FM}_{2}$ & 0.0441 & 0.0925 & 0.0298 & 4 \\
$\mathrm{FM}_{3}$ & 0.0415 & 0.0943 & 0.0386 & 3 \\
$\mathrm{FM}_{4}$ & 0.0481 & 0.1163 & -0.0108 & 2 \\
$\mathrm{FM}_{5}$ & 0.0738 & 0.0581 & 0.0104 & 8 \\
$\mathrm{FM}_{6}$ & 0.0568 & 0.0769 & -0.0063 & 7 \\
$\mathrm{FM}_{7}$ & 0.0709 & 0.0628 & 0.0050 & 0 \\
$\mathrm{FM}_{8}$ & 0.0598 & 0.0708 & 0.0391 & 1 \\
$\mathrm{FM}_{9}$ & 0.0396 & 0.1083 & -0.0436 & 1 \\
$\mathrm{FM}_{10}$ & 0.1182 & 0.0478 & -0.0237 & 9 \\
$\mathrm{FM}_{11}$ & 0.0894 & 0.0522 & -0.0326 & 10 \\
$\mathrm{FM}_{12}$ & 0.0933 & 0.0409 & & \\
\hline
\end{tabular}


TABle 5: Top six FMs as well as the inspection and maintenance measures for them.

\begin{tabular}{|c|c|c|c|}
\hline Ranking & $\mathrm{FM}_{i}$ & Failure mode & Inspection and maintenance measures \\
\hline 1 & $\mathrm{FM}_{9}$ & Rotor breakdown & $\begin{array}{l}\text { Monitor the vibration and temperature of bearings and perform nondestructive inspections } \\
\text { on a regular basis to ensure that there is no degradation of the components. }\end{array}$ \\
\hline 2 & $\mathrm{FM}_{4}$ & & \\
\hline 3 & $\mathrm{FM}_{3}$ & & \\
\hline 4 & $\mathrm{FM}_{2}$ & $\begin{array}{l}\text { Clogged lubricating oil } \\
\text { system }\end{array}$ & $\begin{array}{c}\text { Regular cleaning or replacement of related devices. In addition, the quality of the lubricating } \\
\text { oil must be monitored and tested regularly. }\end{array}$ \\
\hline 5 & $\mathrm{FM}_{6}$ & & \\
\hline 6 & $\mathrm{FM}_{8}$ & $\begin{array}{l}\text { Mechanical transmission } \\
\text { breakdown }\end{array}$ & $\begin{array}{l}\text { Monitor the speed and vibration of the machinery and perform nondestructive tests on a } \\
\text { regular basis. }\end{array}$ \\
\hline
\end{tabular}

TABLE 6: Calculation results and rankings obtained with the three methods.

\begin{tabular}{|c|c|c|c|c|c|c|}
\hline \multirow[t]{2}{*}{$\mathrm{FM}_{i}$} & \multicolumn{2}{|c|}{$\begin{array}{c}\text { Conventional RPN } \\
(S, O \text {, and } D)\end{array}$} & \multicolumn{2}{|c|}{$\begin{array}{l}\text { Cost-based RPN } \\
(S, O, D \text {, and } E)\end{array}$} & \multicolumn{2}{|c|}{ Proposed FMEA method } \\
\hline & RPN & Ranking & RPN & Ranking & $\mathrm{RC}_{i}$ & Ranking \\
\hline $\mathrm{FM}_{1}$ & 36 & 12 & 180 & 12 & -0.0329 & 11 \\
\hline $\mathrm{FM}_{2}$ & 96 & 9 & 480 & 9 & 0.0271 & 4 \\
\hline $\mathrm{FM}_{3}$ & 200 & 1 & 1,000 & 1 & 0.0298 & 3 \\
\hline $\mathrm{FM}_{4}$ & 108 & 7 & 648 & 3 & 0.0386 & 2 \\
\hline $\mathrm{FM}_{5}$ & 120 & 3 & 600 & 5 & -0.0108 & 8 \\
\hline $\mathrm{FM}_{6}$ & 84 & 10 & 420 & 10 & 0.0104 & 5 \\
\hline $\mathrm{FM}_{7}$ & 84 & 10 & 420 & 10 & -0.0063 & 7 \\
\hline $\mathrm{FM}_{8}$ & 112 & 5 & 560 & 7 & 0.0050 & 6 \\
\hline $\mathrm{FM}_{9}$ & 108 & 7 & 756 & 2 & 0.0391 & 1 \\
\hline $\mathrm{FM}_{10}$ & 112 & 5 & 560 & 7 & -0.0436 & 12 \\
\hline $\mathrm{FM}_{11}$ & 120 & 3 & 600 & 5 & -0.0237 & 9 \\
\hline $\mathrm{FM}_{12}$ & 125 & 2 & 625 & 4 & -0.0326 & 10 \\
\hline
\end{tabular}

obtained with the conventional and cost-based RPN methods were somewhat similar. However, certain large differences were observed between them, such as the differences in $\mathrm{FM}_{4}$ and $\mathrm{FM}_{9}$. These differences were caused by the inclusion or exclusion of the expected cost as a risk element in the FMEA. In both the cost-based RPN and proposed methods, $S, O, D$, and $E$ are considered to be risk elements. Nevertheless, the correlation coefficient between the results of the cost-based RPN and proposed methods was 0.4511 . The ranking results obtained with these two methods were different, especially for $\mathrm{FM}_{2}, \mathrm{FM}_{6}, \mathrm{FM}_{10}, \mathrm{FM}_{11}$, and $\mathrm{FM}_{12}$. The proposed method provides a more rational risk assessment than the other two methods because it addresses the drawbacks in the calculation of the RPN. Rezaee et al. [42] increased the cost element in the conventional FMEA model to optimize the model. They applied the optimized model to data in the marble processing industry. Rezaee et al. [42] verified that the analysis results obtained with the optimized FMEA model were closer to reality than the results obtained using the conventional FMEA model. In the proposed method, linguistic variables and rough numbers are used to capture and express analysts' subjective opinions regarding the importance of each risk element in FMEA. The weights of the risk elements were generated using the concept of entropy, and the ranking index was obtained using the modified TOPSIS.

After analyzing the FMEA calculation results, four main differences were observed among the three methods.
4.4.1. Comprehensively Consider Available and Significant Factors for Decision-Making. Three risk elements, namely severity, occurrence, and detection difficulty, are used in the conventional RPN method. However, the conventional RPN method does not encompass the entire range of causal factors. It does not consider the expected cost, which is an important element. If two FMs receive the same ratings for $S$, $O$, and $D$, the FM with a higher expected cost should have a higher priority. It is not possible for any organization, whether a government agency or private enterprise, to assign unlimited resources to ensure the system or product reliability. In Taiwan, the government allocates a certain budget to the Homeland Security Office every year for maintaining critical infrastructure. Therefore, the cost-based RPN and proposed methods, which consider the expected cost as a risk element, are more suitable for obtaining a sufficient decision-making index.

\subsubsection{Evaluate the Ratings and Consider Subjectivity during} FM Evaluation. In the conventional RPN method, the final score of every risk element is derived from the arithmetic average, but information loss may occur during the calculation process. In many cases, the obtained score may be unrepresentative because of some uncertain ratings. However, in the proposed method, the subjectivity and uncertainty in FMEA can be adjusted. The rough number mechanism in the proposed FMEA method can provide reasonable and realistic risk element ratings because the 
Table 7: Main differences in the three methods.

\begin{tabular}{|c|c|c|c|c|}
\hline \multirow{2}{*}{ Method selection } & \multicolumn{4}{|c|}{ Factors considered } \\
\hline & Expected cost consideration & Rating & Consideration of parameter weight & Reduce ranking repeatability \\
\hline Conventional RPN method & Partial & No & No & No \\
\hline Cost-based RPN method & Yes & No & No & Partial \\
\hline Mohsen and Fereshteh [14] & No & No & Yes & Yes \\
\hline Lo and Liou $[8]$ & Yes & No & Yes & Yes \\
\hline Yucesan et al. [36] & No & No & Yes & Yes \\
\hline Proposed FMEA method & Yes & Yes & Yes & Yes \\
\hline
\end{tabular}

flexible and dynamic rough interval represents the subjectivity in the determination of the risk element scores.

\subsubsection{Deploy Objective Weights for Every Risk Element.} The conventional RPN method assumes that every risk element has equal weight. This method fails to examine the importance of each risk element. In addition, some important elements tend to be ignored. In the proposed technique, the entropy weight method, which is based on inherent information, is used to determine the index weight. Therefore, the proposed method not only considers the weight of each element but also determines the weights in an objective manner. Our determining weights method is different from the studies of Lo et al. [9], Lo and Liou [8], and Yucesan and Gul [35], since they generate weights based on the judgment of experts. This method requires the design of another questionnaire (such as AHP, ANP, or BWM questionnaires). Undoubtedly, these documents all pointed out that risk elements $(S, O, D$, and $E)$ should have corresponding importance weights.

4.4.4. Lower the Repetition Ratio for Prioritization. The simple multiplication used in the conventional FMEA means that many repeated ranking values are obtained (Table 6). When the conventional RPN method was used, the third, fifth, seventh, and tenth ranks were repeated twice. The priority orders assessed were identical with a high frequency, and the repetition rate was over $66 \%$. In this situation, the decision-maker may find it difficult to decide which FM to prioritize. With the cost-based RPN method, the repetition rate was less than 50\%. However, the aforementioned problem still persisted. With the proposed method, the repetition rate among all FMs was $0 \%$, which indicates that the method could clearly distinguish the priorities for all the FMs. The main differences between the conventional RPN, cost-based RPN, and proposed methods are presented in Table 7.

On the other hand, we use sensitivity analysis to explore whether changes in risk element weights will affect the ranking of failure modes. The sensitivity analysis method refers to Lo and Liou's [8] study. The severity (the highest risk element weight) among all the risk elements is assigned from 0.1 to 0.9 , with the other weights assigned in proportion. Table 8 presents the results of nine weight configurations. The "severity weight" changes from run 1 to run 9 in units of 0.1 . Figure 2 is the ranking result of the failure mode after nine runs of the sensitivity analysis. Under the
TABLE 8: All the risk element weights change according to severity.

\begin{tabular}{lcccc}
\hline & $S$ & $O$ & $D$ & $E$ \\
\hline Entropy & 0.493 & 0.194 & 0.081 & 0.233 \\
Run 1 & 0.100 & 0.345 & 0.143 & 0.412 \\
Run 2 & 0.200 & 0.306 & 0.127 & 0.367 \\
Run 3 & 0.300 & 0.268 & 0.111 & 0.321 \\
Run 4 & 0.400 & 0.230 & 0.095 & 0.275 \\
Run 5 & 0.500 & 0.191 & 0.079 & 0.229 \\
Run 6 & 0.600 & 0.153 & 0.063 & 0.183 \\
Run 7 & 0.700 & 0.115 & 0.048 & 0.137 \\
Run 8 & 0.800 & 0.077 & 0.032 & 0.092 \\
Run 9 & 0.900 & 0.038 & 0.016 & 0.046 \\
\hline
\end{tabular}

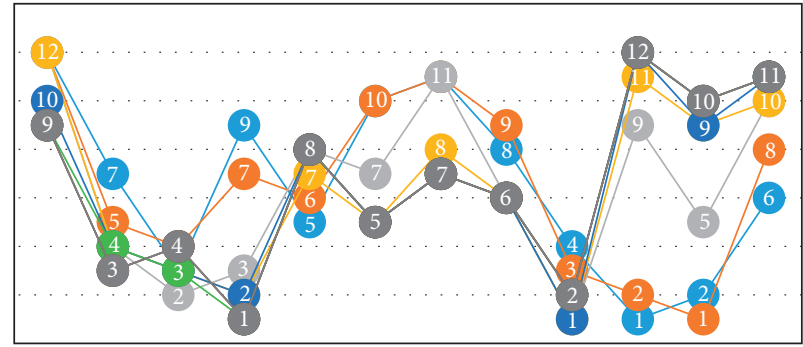

FM1 FM2 FM3 $\quad$ FM4 FM5 FM6 FM7 FM8 FM9 FM10 FM11 FM12

- Run 1

$\rightarrow$ Run 2

- Run 3

$\rightarrow$ Run 4

$\rightarrow$ Run 5

FIGURE 2: The ranking result of the failure mode after nine runs of the sensitivity analysis.

change of the risk element $S$, the failure modes will have a significant change, which means that our model is highly sensitive to the change of the risk element weight. Therefore, the relative importance of risk elements must be evaluated. In this case, it is reasonable to use entropy to determine the objective weights of the risk elements, and the analysis results are also unanimously approved by experts.

\section{Conclusions and Remarks}

Critical infrastructure systems are important for the normal functioning of society and economic development [43]. Natural disasters and accidents are often not predictable in advance. Adopting suitable prevention strategies can significantly reduce the cost and time of reconstruction after a 
disaster. Many major incidents of critical infrastructure failure have occurred, and governments have actively developed risk management policies to cope with them. The FMEA method, which can reveal the potential causes and problems of failure modes during the process of risk evaluation, is widely used in many fields to control the stability and reliability of any facility [36, 44, 45]. However, some intrinsic problems in the conventional FMEA method exist. The entropy-based rough FMEA method proposed in this study has four advantages, which can alleviate the problems of the conventional FMEA method. The proposed approach considers the uncertainty of information provided by analysts with varied backgrounds. It determines the weight of the relationship among evaluation parameters and reduces the repetition rate for prioritization. Consequently, decisionmakers can more effectively identify high-risk FMs and take the appropriate corresponding measures in advance.

To validate the applicability of the proposed approach under a vague and subjective environment, an illustrative example, for a nuclear power plant, was taken into consideration. Via the collection of data from the analysts, the results obtained using three risk-assessment methods, namely the conventional RPN, cost-based RPN, and proposed methods, were compared. The comparison reveals that the proposed method provides a more reasonable and robust ranking system than the other two methods. Sensitivity analysis also confirmed the necessity of risk elements weights evaluation. Decision-makers or risk analysts can use the failure mode risk ranking to determine which part we first maintain and improve. The concept of this article overcomes the traditional methods of qualitative risk assessment. It is feasible and effective to show the degree of risk of failure modes through quantitative calculations. In addition to steam turbine failure mode assessment, the proposed method can also be applied to other nuclear power plant systems or components. Future studies can apply the proposed methodology in other interdisciplinary fields.

\section{Appendix}

\section{A. Example of Rough Number Calculation}

For the fourth $\mathrm{FM}\left(\mathrm{FM}_{4}\right)$, the 24 analysts' crisp rankings are $10,10,10,10,10,10,10,10,10,10,7,10,10,9,9,8,10,8,9,8$, $10,9,9$, and 9 . By applying the rough number calculation process, the rough interval of the severity importance for the fourth FM is obtained as described in the following text.

Step 1. Obtain the lower and upper limits of the rough numbers

$$
\begin{aligned}
\underline{\operatorname{Lim}}(10)= & \frac{1}{24}(10+10+\cdots+9)=9.375, \overline{\operatorname{Lim}}(10)=\frac{14}{14}(10+10+\cdots+10)=10, \\
& \Rightarrow \operatorname{RN}(10)=[9.375,10], \\
\underline{\operatorname{Lim}}(7)= & \frac{1}{1}(7)=7, \overline{\operatorname{Lim}}(7)=\frac{1}{24}(10+10+\cdots+9)=9.375, \\
& \Rightarrow \operatorname{RN}(7)=[7,9.375], \\
\underline{\operatorname{Lim}}(9)= & \frac{1}{10}(7+9+\cdots+9)=8.5, \overline{\operatorname{Lim}}(9)=\frac{1}{20}(10+10+\cdots+9)=9.7, \\
& \Rightarrow \operatorname{RN}(9)=[8.5,9.7], \\
\underline{\operatorname{Lim}}(8)= & \frac{1}{4}(7+8+8+8)=7.75, \overline{\operatorname{Lim}}(8)=\frac{1}{23}(10+10+\cdots+9)=9.478, \\
& \Rightarrow \operatorname{RN}(8)=[7.75,9.478] .
\end{aligned}
$$

Step 2. Obtain the interval values of the rough numbers

The set of scores can be obtained by averaging as follows:

$$
\operatorname{RN}\left(a_{4 S}\right)=\left[\frac{(9.375+7+8.5+7.75)}{4}, \frac{(10+9.375+9.7+9.478)}{4}\right]=[8.854,9.834]
$$




\section{Data Availability}

All data generated or analysed during the study are included in this published article.

\section{Conflicts of Interest}

All authors declare that they have no conflicts of interest.

\section{Authors' Contributions}

H.-W.L. and Y.-H. L. contributed to the conceptualization; H.-W.L. contributed to the methodology; J.J-H. L. and C.-N. H. contributed to the investigation; J.-J. Y. and C.-N. H. contributed to data curation; H.-W.L. and Y.-H.L. contributed to preparing the original draft; J.J-H. L. performed the review and editing work; and J.-J. Y. and C.-N. H contributed to the project administration. All authors have read and agreed to the final version of the manuscript.

\section{References}

[1] L. M. Shakou, J.-L. Wybo, G. Reniers, and G. Boustras, "Developing an innovative framework for enhancing the resilience of critical infrastructure to climate change," Safety Science, vol. 118, pp. 364-378, 2019.

[2] F. Aros-Vera, S. Gillian, A. Rehmar, and L. Rehmar, "Increasing the resilience of critical infrastructure networks through the strategic location of microgrids: a case study of Hurricane Maria in Puerto Rico," International Journal of Disaster Risk Reduction, vol. 55, Article ID 102055, 2021.

[3] E. G. Quijano, D. Ríos Insua, and J. Cano, "Critical networked infrastructure protection from adversaries," Reliability Engineering \& System Safety, vol. 179, pp. 27-36, 2018.

[4] J.-S. Chou and C. S. Ongkowijoyo, "Hybrid decision-making method for assessing interdependency and priority of critical infrastructure," International Journal of Disaster Risk Reduction, vol. 39, Article ID 101134, 2019.

[5] C.-N. Huang, J. J. H. Liou, and Y.-C. Chuang, "A method for exploring the interdependencies and importance of critical infrastructures," Knowledge-Based Systems, vol. 55, pp. 66-74, 2014.

[6] F. Wang, J. J. Magoua, N. Li, and D. Fang, "Assessing the impact of systemic heterogeneity on failure propagation across interdependent critical infrastructure systems," International Journal of Disaster Risk Reduction, vol. 50, p. 101818, 2020.

[7] H. H. Xie, F. Zhang, Y. Y. He, J. C. Yang, and W. Q. Ma, "Research on digital prototype technologies of personnel airlock for nuclear power plant," in Proceedings of the 2018 International Conference on Power System Technology (POWERCON), pp. 4684-4691, IEEE, Guangzhou, China, November 2018.

[8] H.-W. Lo and J. J. H. Liou, "A novel multiple-criteria decision-making-based FMEA model for risk assessment," Applied Soft Computing, vol. 73, pp. 684-696, 2018.

[9] H.-W. Lo, J. J. H. Liou, C.-N. Huang, and Y.-C. Chuang, “A novel failure mode and effect analysis model for machine tool risk analysis," Reliability Engineering \& System Safety, vol. 183, pp. 173-183, 2019.

[10] H.-C. Liu, J.-X. You, and C.-Y. Duan, "An integrated approach for failure mode and effect analysis under interval- valued intuitionistic fuzzy environment," International Journal of Production Economics, vol. 207, pp. 163-172, 2019.

[11] H.-C. Liu, J.-X. You, X.-F. Ding, and Q. Su, "Improving risk evaluation in FMEA with a hybrid multiple criteria decision making method," International Journal of Quality \& Reliability Management, vol. 32, no. 7, pp. 763-782, 2015.

[12] W. Wang, X. Liu, X. Chen, and Y. Qin, "Risk assessment based on hybrid FMEA framework by considering decision maker's psychological behavior character," Computers \& Industrial Engineering, vol. 136, pp. 516-527, 2019.

[13] J. Qin, Y. Xi, and W. Pedrycz, "Failure mode and effects analysis (FMEA) for risk assessment based on interval type-2 fuzzy evidential reasoning method," Applied Soft Computing, vol. 89, Article ID 106134, 2020.

[14] O. Mohsen and N. Fereshteh, "An extended VIKOR method based on entropy measure for the failure modes risk assessment - a case study of the geothermal power plant (GPP)," Safety Science, vol. 92, pp. 160-172, 2017.

[15] H. Zhang, Y. Dong, I. Palomares-Carrascosa, and H. Zhou, "Failure mode and effect analysis in a linguistic context: a consensus-based multiattribute group decision-making approach," IEEE Transactions on Reliability, vol. 68, no. 2, pp. 566-582, 2018.

[16] J. Xiao, X. Wang, and H. Zhang, "Exploring the ordinal classifications of failure Modes in the reliability management: an optimization-based consensus model with bounded confidences", Group Decision and Negotiation, Springer, Berlin, Germany, 2021.

[17] M. Gul, B. Guven, and A. F. Guneri, "A new Fine-Kinneybased risk assessment framework using FAHP-FVIKOR incorporation," Journal of Loss Prevention in the Process Industries, vol. 53, pp. 3-16, 2018.

[18] M. Alrifaey, T. Sai Hong, E. Supeni, A. As'arry, and C. Ang, "Identification and prioritization of risk factors in an electrical generator based on the hybrid FMEA framework," Energies, vol. 12, no. 4, p. 649, 2019.

[19] S. Yousefi, A. Alizadeh, J. Hayati, and M. Baghery, "HSE risk prioritization using robust DEA-FMEA approach with undesirable outputs: a study of automotive parts industry in Iran," Safety Science, vol. 102, pp. 144-158, 2018.

[20] M. Gul, M. F. Ak, and A. F. Guneri, "Pythagorean fuzzy VIKOR-based approach for safety risk assessment in mine industry," Journal of Safety Research, vol. 69, pp. 135-153, 2019.

[21] H.-C. Liu, J.-X. You, Y.-Z. Chen, and X.-J. Fan, "Site selection in municipal solid waste management with extended VIKOR method under fuzzy environment," Environmental Earth Sciences, vol. 72, no. 10, pp. 4179-4189, 2014.

[22] M. M. Silva, A. P. H. de Gusmão, T. Poleto, L. C. e. Silva, and A. P. C. S. Costa, "A multidimensional approach to information security risk management using FMEA and fuzzy theory," International Journal of Information Management, vol. 34, no. 6, pp. 733-740, 2014.

[23] H. Safari, Z. Faraji, and S. Majidian, "Identifying and evaluating enterprise architecture risks using FMEA and fuzzy VIKOR," Journal of Intelligent Manufacturing, vol. 27, no. 2, pp. 475-486, 2016.

[24] W. Suo, J. Zhang, and X. Sun, "Risk assessment of critical infrastructures in a complex interdependent scenario: a fourstage hybrid decision support approach," Safety Science, vol. 120, pp. 692-705, 2019.

[25] E. Roe and P. R. Schulman, "A reliability \& risk framework for the assessment and management of system risks in critical 
infrastructures with central control rooms," Safety Science, vol. 110 , pp. $80-88,2018$.

[26] C. Große and P. M. Olausson, "Blind spots in interaction between actors in Swedish planning for critical infrastructure protection," Safety Science, vol. 118, pp. 424-434, 2019.

[27] R. Lin, Y. Man, C. K. M. Lee, P. Ji, and J. Ren, "Sustainability prioritization framework of biorefinery: a novel multi-criteria decision-making model under uncertainty based on an improved interval goal programming method," Journal of Cleaner Production, vol. 251, Article ID 119729, 2020.

[28] L. Wang, F. Yan, F. Wang, and Z. Li, "FMEA-CM based quantitative risk assessment for process industries-A case study of coal-to-methanol plant in China," Process Safety and Environmental Protection, vol. 149, pp. 299-311, 2021.

[29] M. Mei and Z. Chen, "Evaluation and selection of sustainable hydrogen production technology with hybrid uncertain sustainability indicators based on rough-fuzzy BWM-DEA," Renewable Energy, vol. 165, pp. 716-730, 2021.

[30] E. K. Tekez, "Failure modes and effects analysis using fuzzy topsis in knitting process," Tekstil ve Konfeksiyon, vol. 28, no. 1, pp. 21-26, 2018.

[31] J. Joseph, K. V. Sriram, A. O. Mathew, and A. Kanoor, "The failure mode effects analysis to prevent delays for development projects in aerospace industry-a case study," International Journal of Mechanical and Production Engineering Research and Development, vol. 9, no. 2, pp. 123-136, 2019.

[32] D. M. Popa, "Engineering risk of series production in automotive industry," Management Systems in Production Engineering, vol. 27, no. 1, pp. 5-11, 2019.

[33] A. Mora, L. Ayala, R. Bielza, F. Ataúlfo González, and A. Villegas, "Improving safety in blood transfusion using failure mode and effect analysis," Transfusion, vol. 59, no. 2, pp. 516-523, 2019.

[34] M. Gul and M. F. Ak, "A modified failure modes and effects analysis using interval-valued spherical fuzzy extension of TOPSIS method: case study in a marble manufacturing facility," Soft Computing, vol. 25, no. 8, pp. 6157-6178, 2021.

[35] M. Yucesan and M. Gul, "Failure modes and effects analysis based on neutrosophic analytic hierarchy process: method and application," Soft Computing, vol. 25, pp. 1-18, 2021.

[36] M. Yucesan, M. Gul, and E. Celik, "A holistic FMEA approach by fuzzy-based Bayesian network and best-worst method," Complex \& Intelligent Systems, vol. 7, pp. 1-18, 2021.

[37] Z. a. Pawlak, "Rough sets," International Journal of Computer \& Information Sciences, vol. 11, no. 5, pp. 341-356, 1982.

[38] Z. Pawlak, "Rough sets: theoretical aspects of reasoning about data," Springer Science \& Business Media, vol. 9, 2012.

[39] C. E. Shannon, "A mathematical theory of communication," Bell System Technical Journal, vol. 27, no. 3, pp. 379-423, 1948.

[40] C. L. Hwang and K. S. Yoon, Multiple Attribute Decision Making: Methods and Applications, Springer-Verlag, Berlin, 1981.

[41] T. Kuo, "A modified TOPSIS with a different ranking index," European Journal of Operational Research, vol. 260, no. 1, pp. 152-160, 2017.

[42] M. J. Rezaee, A. Salimi, and S. Yousefi, "Identifying and managing failures in stone processing industry using costbased FMEA," International Journal of Advanced Manufacturing Technology, vol. 88, no. 9-12, pp. 3329-3342, 2017.

[43] H.-W. Lo, J. J. H. Liou, C.-N. Huang, Y.-C. Chuang, and G.-H. Tzeng, "A new soft computing approach for analyzing the influential relationships of critical infrastructures,"
International journal of critical infrastructure protection, vol. 28, Article ID 100336, 2020.

[44] S. Yousefi, M. Valipour, and M. Gul, "Systems failure analysis using Z-number theory-based combined compromise solution and full consistency method," Applied Soft Computing, vol. 113, Article ID 107902, 2021.

[45] H.-W. Lo, C.-C. Hsu, C.-N. Huang, and J. J. H. Liou, "An ITARA-TOPSIS based integrated assessment model to identify potential product and system risks," Mathematics, vol. 9, no. 3, p. 239, 2021. 